\title{
ARTIGOS
}

\section{Classe hospitalar: práticas pedagógicas desenvolvidas com crianças dos anos iniciais do ensino fundamental}

Thais Paes Custódio Milena Bartolomei Silva

\begin{abstract}
RESUMO: A classe hospitalar é um dos campos de atuação que estão disponíveis para os pedagogos. Entretanto, durante o processo de formação, os acadêmicos recebem poucas informações acerca dessa área de trabalho ou até mesmo a desconhecem, o que interfere nas futuras atividades educacionais. Frente ao exposto, o objetivo deste trabalho foi buscar informações acerca do processo de formação e das práticas pedagógicas desenvolvidas por profissionais da Educação que atuam na classe hospitalar de um hospital público em Campo Grande/MS. Para o desenvolvimento da pesquisa, foi utilizada uma metodologia qualitativa com os profissionais que atuam nas classes hospitalares do referido hospital. A coleta de dados ocorreu por meio de entrevistas, elaboradas a partir de um questionário semiestruturado (o que permite ao entrevistado expressar-se com mais liberdade). Os resultados apresentados indicam formas de atuação e boas práticas e podem contribuir para o levantamento de novos questionamentos e, consequentemente, para a promoção de novos estudos e pesquisas no que se refere às classes hospitalares.
\end{abstract}

PALAVRAS-CHAVE: Classe Hospitalar. Práticas Pedagógicas. Formação Acadêmica.

\section{Hospital class: pedagogical practices developed with children in the years of fundamental education}

\begin{abstract}
The hospital class is one of the action fields that are available to educators. However, during the training process, academics receive little or no information about this area, or even unaware of it, what interferes with future educational activities. Therefore, the objective of this study was to obtain information about the training process and the pedagogical practices that are developed by the Education professionals who work in a hospital class of a public hospital in Campo Grande/MS. For the development of the research, a qualitative methodology was used with the professionals that work in the hospital classes of the referred institution. Data were collected through interviews, based on a semi-structured questionnaire (which allows the interviewee to express himself more freely). The results presented indicate ways of acting and good practices and may contribute to the raising of new discussions and, consequently, to the promotion of new studies and researches regarding the hospital classes.
\end{abstract}

KEYWORDS: Hospital Class. Pedagogical practices. Academic education. 


\section{autêntica}

DOI https://doi.org/10.31639/rbpfp.v\%vi\%i.34

\section{INTRODUÇÃO}

Durante o curso de licenciatura em Pedagogia da Universidade Federal de Mato Grosso do Sul e nas discussões do grupo de estudo da linha de pesquisa Educação, Saúde e Práticas Educacionais do grupo de Estudos e Pesquisas sobre Educação, Desenvolvimento humano e Inclusão (GEPEDHI), iniciou-se essa reflexão acerca da perspectiva de estarem sendo garantidos os direitos das crianças e dos adolescentes no ambiente hospitalar deste país. Compreendemos, inicialmente, que já ocorreram significativas conquistas nessa área, na sociedade brasileira, para a população infanto-juvenil e que sempre precisará haver um movimento na dinâmica dos contextos histórico-sociais.

Destarte, a conquista desses direitos ocorreu, de maneira muito expressiva, no artigo 227 da Constituição Federal de 1988:

Art. 227. É dever da família, da sociedade e do Estado assegurar à criança, ao adolescente e ao jovem, com absoluta prioridade, o direito à vida, à saúde, à alimentação, à educação, ao lazer, à profissionalização, à cultura, à dignidade, ao respeito, à liberdade e à convivência familiar e comunitária, além de colocá-los a salvo de toda forma de negligência, discriminação, exploração, violência, crueldade e opressão. (BRASIL,1988).

Mediante a esse artigo da Constituição, ainda nos questionamos, se de fato é garantido às crianças hospitalizadas o direito a educação, a saúde, a vida e ao lazer. O que aqui, neste estudo, queremos verificar mais especificamente é a respeito da legislação brasileira quanto aos direitos das crianças e dos adolescentes hospitalizados, e a necessidade da criação de um espaço adequado nos ambientes hospitalares, com um currículo flexibilizado que propicie o desenvolvimento infantil.

A classe hospitalar, no Brasil, ainda é pouco difundida, com poucos estudos e pesquisas sobre o tema. Muitas vezes os estudantes de Pedagogia, mesmo já em fase de conclusão do curso, pouco sabem ou até mesmo desconhecem esse campo de atuação, que também está disponível, conforme apontam Saldanha e Simões (2013, p. 447): "[...] no Brasil, o início dessa ação educacional em ambiente não convencional é ainda pouco explorada e apresenta muitas lacunas." Alguns estudos datam de 1902, ou seja, há mais de um século, iniciaram as primeiras práticas de escolarização em ambiente hospitalar, tendo ocorrido especificamente no Hospício Nacional de Alienados, no Rio de Janeiro (SALDANHA e SIMÕES, 2013).

Como se viu na legislação, saúde e educação são direitos assegurados pela Constituição Federal de 1988. Além disso, no artigo 208, inciso III, pontua o atendimento educacional especializado - AEE para pessoas com deficiência, isso devendo ocorrer de preferência em instituições de ensino regulares. Quanto ao atendimento educacional especializado para estudantes hospitalizados, na chamada classe hospitalar, no Brasil, esse recurso foi instituído pela Lei Federal n 9.394, de 20 de dezembro de 1996, ou seja, a Lei de Diretrizes e Bases da Educação Nacional - LDBEN ou, simplesmente, LDB. No seu artigo 58, parágrafo $2^{\circ}$, consta: "O atendimento educacional será feito em classes, escolas ou serviços especializados, sempre que, em função das condições específicas dos alunos, não for possível a sua integração nas classes comuns de ensino regular".

O atendimento educacional para as crianças, no ambiente hospitalar, aumentou desde a década de 1990, com a Lei Federal n 8.069, de 13 de julho de 1990, que institui o Estatuto da Criança e do Adolescente ECA, mais a Resolução n 41/MEC/Conanda, de 13 de outubro de 1995, Diretrizes Nacionais para a Educação Especial na Educação Básica, além da LDBEN de 1996, dentre outros dispositivos. Essa legislação permite 


\section{autêntica}

DOI https://doi.org/10.31639/rbpfp.v\%vi\%i.34

compreender a importância que se tem dado à continuidade no processo de aprendizagem das crianças e dos adolescentes, dentro e fora do ambiente escolar.

Com isso, este trabalho vem ao encontro de novos conhecimentos que possam já existir, de forma que o assunto abordado venha a ser ampliado, considerando que existem acadêmicos e profissionais de educação que não possuem informações acerca da classe hospitalar e, tampouco, das práticas pedagógicas desenvolvidas dentro dos hospitais que atendem crianças e adolescentes.

Observando as práticas pedagógicas existentes nas classes hospitalares, buscamos caracterizar os profissionais de educação que atuam na classe hospitalar, identificando-os a partir das práticas pedagógicas nesse ambiente, e como se dá essa atuação junto às crianças hospitalizadas, mostrando os maiores desafios que enfrentam nessa especialidade. Como se trata de pesquisa com seres humanos, este trabalho foi concedido pelo comitê de ética, autorização do CAAE/UFMS: 62205216.6.0000.0021, para o desenvolvimento desta pesquisa.

\section{CLASSE HOSPITALAR: UMA ABORDAGEM HISTÓRICA}

A medicina leiga surgiu na Grécia Antiga e, ao longo dos séculos, novas descobertas e mudanças ocorreram. Foi somente lá pelo século XII que, na Europa, instituições como hospitais foram desenvolvidas e estruturadas, mas somente "à época do Renascimento é que realmente se nota um grande desenvolvimento na saúde pública, período em que os homens começaram a se interessar, cada vez mais, pela tecnologia visando o poder e a ganância de vencer guerras" (SANDRONI, 2011, p. 5).

A preocupação com a saúde pública e com o bem-estar social cresceu ainda mais na Era Moderna devido às questões de manutenção econômica de mercado, pois, para que os índices de produção das fábricas não diminuíssem, era necessário que a população trabalhadora estivesse com a saúde em boas condições. Sendo que, naquele período histórico, a mão-de-obra utilizada não era somente de homens, mas também de mulheres e até de crianças, conforme aponta Sandroni:

Destarte, a produção passa a ser fundamental para a economia no século XVII, e o trabalho é essencial para a produção de riquezas da nação. Neste caso, quanto mais trabalhadores sadios, maior a produtividade; portanto, qualquer perda ou diminuição de produtividade devido a uma enfermidade era prejudicial para a economia. Ainda hoje, na modernidade, perpetua-se tal condição. (2011, p. 6).

Para o autor, no Brasil, somente com a industrialização e a urbanização, fenômenos que ocorreram na Era Vargas nas décadas de 1930 e de 1940, é que passaram a surgir as primeiras iniciativas de uma medicina social para atender às necessidades de atenção à saúde dos trabalhadores industriais nas cidades maiores do país. Essas iniciativas de uma medicina social constituíram um razoável contraste com a realidade histórica em que o país estava inserido anteriormente, pois, até o século XVIII, sequer havia uma medicina oficial:

No Brasil, até o século XVIII, não existia uma medicina oficial, os doentes eram tratados por curandeiros, feiticeiros e, posteriormente, pelos jesuítas. Os médicos eram habilitados na metrópole portuguesa e trabalhavam em instituições filantrópicas ou na assistência privada. (SANDRONI, 2011, p. 7).

Trazendo a discussão para a questão da saúde de crianças e de adolescentes, cabe voltar à leitura de Sandroni (2011) citando Vasconcellos (2006), informando que, em regiões próximas a Paris, em 1935, Henri Sellier havia inaugurado uma escola para crianças inadaptadas, que seria uma das primeiras experiências envolvendo o 


\section{autêntica}

DOI https://doi.org/10.31639/rbpfp.v\%vi\%i.34

processo de escolarização em ambiente hospitalar. Posteriormente, o primeiro registro de classe hospitalar no Brasil data de 1950, no Hospital Municipal Jesus, no Rio de Janeiro, com o atendimento voltado para o público infantil: "Esta classe iniciou oficialmente suas atividades em 14 de agosto de 1950 [...]." (SANDRONI, 2011, p. 13).

Nessa nossa busca por informações acerca de classe hospitalar no país, foi possível observar que, efetivamente, a preocupação e a garantia da oferta do ensino escolar, fora dos muros da escola, pode ser percebida como evidenciada na década de 1980, acabando o assunto por constar na Constituição Federal homologada em 1988. Essa conquista está diretamente ligada ao contexto histórico, social, econômico e político vivenciado na época, considerando que diferentes grupos sociais buscavam melhorias para o país e colocavam expectativas na elaboração da Lei Maior, de modo que pudesse ser um instrumento de garantia e de efetivação dos direitos inerentes às necessidades emergentes, conforme pontuam Drabach e Souza: “[...] esse movimento pela democratização da educação resultou na inserção do princípio constitucional de gestão democrática da escola pública" (DRABACH e SOUZA, 2014, p. 224).

A partir do período citado, a educação foi colocada em pauta com olhares mais atentos, buscando articular a realidade do contexto com as práticas no ambiente escolar. Nessa perspectiva, é possível observar que houve um avanço, pois o documento maior possui não só um artigo dedicado à educação, mas também garante, pela primeira vez, o atendimento especializado para os estudantes que possuem necessidades educacionais especiais. Mesmo assim, entretanto, ainda não instituído o atendimento especializado fora do ambiente escolar. Conforme expressa Sandroni:

No Brasil tem-se conhecimento da existência desse serviço desde 1950 e sua expansão, mesmo que tímida, ocorreu depois da segunda metade da década de 1990, devido ao reconhecimento e a importância desse atendimento e sua regularização através da legislação, como, por exemplo, a Lei de Diretrizes e Bases da Educação Nacional N. ${ }^{\circ}$ 9.394/96, que assegura que o atendimento educacional realizado em outro ambiente caso não seja possível a integração do aluno na classe comum do ensino regular. (2011, p.1).

Na década de 1990 surgem outros dispositivos legais que tratam dos direitos das crianças, incluindo o acesso à educação e à saúde, de forma mais específica, como, por exemplo, o Estatuto da Criança e do Adolescente $\triangle E C A$. que trata dos direitos da criança e adolescente para que tenham um desenvolvimento integral, o que envolve as questões de educação, saúde, alimentação, moradia e relações sociais, como disposto nos artigos $3 .^{\circ}, 4 .^{\circ}, 7 .^{\circ}, 11 .^{\circ}, 16 .^{\circ}$ e $19 .^{\circ}$. No documento referido, no artigo 16 consta:

Art. 16. O direito à liberdade compreende os seguintes aspectos:

I - ir, vir e estar nos logradouros públicos e espaços comunitários, ressalvadas as restrições legais;

II - opinião e expressão;

III - crença e culto religioso;

IV - brincar, praticar esportes e divertir-se;

V - participar da vida familiar e comunitária, sem discriminação;

VI - participar da vida política, na forma da lei;

VII - buscar refúgio, auxílio e orientação.

O ECA (1990) trata de diferentes questões acerca dos direitos das crianças e dos adolescentes, entretanto não é explicitado o atendimento educacional em espaço não escolar.

Na Resolução n 41/MEC/Conanda, de 13 de outubro de 1995, que trata dos direitos das crianças e dos adolescentes hospitalizados, consta, no item 9, a garantia de atividades de recreação e de acompanhamento 


\section{autêntica}

DOI https://doi.org/10.31639/rbpfp.v\%vi\%i.34

do currículo escolar durante o período de internação: “Direito a desfrutar de alguma forma de recreação, programas de educação para a saúde, acompanhamento do curriculum escolar, durante sua permanência hospitalar [...]" (BRASIL, 1995, p. 59).

A Lei de Diretrizes e Bases da Educação Nacional de 1996, como já citada anteriormente, explicita o direito das crianças e dos adolescentes de receberem o atendimento educacional em ambientes não escolares, o que possibilitou a garantia do ensino nas classes hospitalares. Entretanto, a inserção dessa garantia na lei não significou a sua efetivação na prática, conforme foi constatado na pesquisa, considerada pioneira, realizada por Fonseca (1999), com intuito de investigar as classes hospitalares no país.

\section{A CLASSE HOSPITALAR E A FORMAÇÃO PROFISSIONAL DOS EDUCADORES}

O atendimento educacional especializado fora do ambiente escolar para os indivíduos que, por algum motivo, seja por deficiência ou por doença, dentre outros fatores, e que podem envolver uma demanda temporária ou permanente, está previsto em leis, sendo explicitado na LDBEN de 1996. Nessa perspectiva é que a classe hospitalar pode ser apontada como uma (intermodalidade) da Educação Especial. Como as Diretrizes da Educação Especial na Educação Básica (2001) define-se o atendimento nas classes hospitalares:

O atendimento educacional especializado pode ocorrer fora de espaço escolar, sendo, nesses casos, certificada a frequência do aluno mediante relatório do professor que o atende:

a) Classe Hospitalar: serviço destinado a prover, mediante atendimento especializado, a educação escolar a alunos impossibilitados de frequentar as aulas em razão de tratamento de saúde que implique internação hospitalar ou atendimento ambulatorial. (BRASIL, 2001, p. 51).

A classe hospitalar está inserida na Educação Especial e é vista como um dos campos para as práticas pedagógicas inclusivas, o que possibilita aos educandos a participação nos processos educativos e o acesso aos conhecimentos escolares de modo a promover interação com o meio social e emancipação dos sujeitos, considerando os aspectos afetivos e históricos, com a valorização das diferenças de forma propulsora para os processos de ensino e de aprendizagem, conforme consta nas Diretrizes Nacionais para a Educação Especial na Educação Básica:

A educação especial deve ocorrer em todas as instituições escolares que ofereçam os níveis, etapas e modalidades da educação escolar previstos na LDBEN, de modo a propiciar o pleno desenvolvimento das potencialidades sensoriais, afetivas e intelectuais do aluno, mediante um projeto pedagógico que contemple, além da orientações comuns- cumprimento dos 200 dias letivos, horas aula, meios para recuperação e atendimento do aluno, avaliação e certificação, articulação com as famílias e a comunidade- um conjunto de outros elementos que permitem definir objetivos, conteúdos e procedimentos relativos à própria dinâmica escolar

Assim sendo, a educação especial deve ocorrer nas escolas públicas e privadas da rede regular de ensino, com base nos princípios da escola inclusiva. Essas escolas, portanto, além do acesso à matricula, devem assegurar as condições para o sucesso escolar de todos os alunos.

Extraordinariamente, os serviços de educação especial podem ser oferecidos em classe especiais, escolas especiais, classes hospitalares e em ambiente domiciliar (BRASIL, 2001, p. 41-42). 


\section{autêntica}

DOI https://doi.org/10.31639/rbpfp.v\%vi\%i.34

Quando o assunto da classe hospitalar é levantada nos diálogos, muitas vezes as ideias iniciais estão relacionadas diretamente com o campo da saúde e sem articular a área educacional. Isso ocorre porque muitos profissionais da educação pouco sabem ou até mesmo desconhecem essa alternativa de ensino como um campo possível de atuação docente.

A insuficiência de teorias e estudos desta natureza em território brasileiro gera, tanto na área educacional, quanto na área de Saúde, o desconhecimento não só para viabilizar a continuidade da escolaridade àquelas crianças e adolescentes que requerem internação hospitalar, mas também para integralizar a atenção de saúde e potencializar o tratamento e o cuidado prestados à criança e ao adolescente. (FONSECA, 1999, p. 7).

A falta de informações, de estudos aprofundados, de teorias e de metodologias revela como tem sido abordada a classe hospitalar no período de formação inicial dos professores:

Nos últimos vinte anos grandes avanços e conquistas aconteceram para a escolarização de crianças e jovens dentro de hospitais, principalmente no que diz respeito à estrutura, funcionamento, currículo e práticas inovadoras de educação; mas ainda há muito a ser investigado. (SALDANHA; SIMÕES, 2013, p. 449).

Os dados apresentados pelo estudo de Saldanha e Simões (2013) revelam que a ausência de dados acerca da formação de professores para atuar nas classes hospitalares pode incorrer em ações pedagógicas não articuladas com uma fundamentação teórica, com a prática e as tomadas de decisão, frente aos educandos hospitalizados. Podem também adquirir um caráter automatizado e até sem reflexão sobre os impactos no cotidiano do educandos hospitalizados.

Esse aspecto de crescimento referente a pesquisas acerca das classes hospitalares no país pode ser considerado positivo em uma perspectiva de que ainda há muito trabalho a ser feito: "Refletir sobre a atuação de pedagogos em hospitais tem sido uma questão bastante delicada na recente, mas já polêmica, discussão sobre a prática pedagógica em enfermarias pediátricas" (FONTES, 2005 apud SILVA, 2015, p. 49).

O artigo de Barros (2007) discute o tema da formação de pedagogos e professores para as classes hospitalares. Essa discussão é feita em uma perspectiva multidisciplinar, que possibilita acesso ao campo de conhecimentos, proporcionando fundamentação teórica que, por conseguinte, reflitam uma prática pedagógica de qualidade. $\mathrm{O}$ artigo aponta que a formação docente é um elemento importante para o processo educativo: “[...] a formação profissional para professores e pedagogos de classes hospitalares requer o reconhecimento e a afirmação de um campo do saber essencialmente multiepistêmico" (BARROS, 2007, p. 264).

A atuação em ambiente hospitalar exige uma formação que permita ao profissional da educação, além de compreender conceitos e teorias sobre o desenvolvimento humano, os processos de aprendizagem, metodologias, aspectos legais, estudos acerca de higiene e saúde dentro do hospital, trabalho com equipe multidisciplinar, dentre outros conhecimentos que permeiam a preparação inicial e continuada. É necessário que os profissionais que atuam nas classes hospitalares tenham habilidades e competências, conforme aponta a mencionada autora: 


\title{
autêntica
}

DOI https://doi.org/10.31639/rbpfp.v\%vi\%i.34

\begin{abstract}
presença de área disponível para a realização das atividades lúdicas, pedagógicas, realização das atividades lúdicas, pedagógicas, recreativas; densidade de leitos na enfermaria pediátrica e dinâmica da utilização do espaço; rotinas de cuidados e atenção destinados às crianças em tratamento, bem como agenda de horários a estas atividades relacionados; avaliação do perfil epidemiológico da clientela atendida (quanto ao tipo de debilidades clínicas e limitações implicadas pelas doenças sofridas pelos jovens pacientes e quanto à recorrência das internações);levantamento do perfil sócio-educacional da clientela atendida: procedência do domicílio da criança, renda familiar e escolaridade do pais, referência a abandono, repetência ou exclusão escolar sofridas pela criança anteriormente à instalação da morbidade
\end{abstract}

capacidade de, quando implantar uma nova classe hospitalar, apreciar a existência de outras medidas humanizadoras ( como presença de brinquedoteca, atuação periódica de recreadores voluntários e presença dos pais como acompanhantes integrais à internação) e integrá-las às atividades correntes de uma classe hospitalar;

capacidade de, quando na presença, por exemplo, de profissionais do tipo atores clown, sugerir modos criativos e funcionais de explorarem os espaços e as rotinas hospitalares, de modo que esses possam compor harmonicamente os momentos de expressão dramática requeridos em dinâmicas de teatro;

capacidade de, quando da ocorrência desses momentos, adaptar flexivelmente as atividades de ensino e aprendizagem das crianças e adolescentes hospitalizados ou aquelas atividades terapêuticas destinadas a colaborarem no enfrentamento psíquico da hospitalização:

capacidade de propor maneiras e materiais alternativos na confecção de jogos e brinquedos;

capacidade de sugerir modos mais apropriados de diagnosticar as demandas de acompanhamento escolar do paciente, modos que o contemple na integralidade de sua condição humana e indissociabilidade de suas necessidades- física, psíquica, social de gênero, e de outra variáveis. (BARROS, 2007, p. 266).

Desde modo, torna-se importante reconhecer o campo de atuação do Pedagogo no contexto não escolar, mostrando que a classe hospitalar é organizada sob diversos aspectos, integrando a escola, o contexto familiar, a saúde, criança/adolescente, etc. possibilitando a ação educativa, contribuindo assim, para o aprendizado das crianças hospitalizadas.

Com isso, esta pesquisa foi iniciada, na perspectiva de buscar informações acerca da formação profissional dos professores atuantes nas classes hospitalares de Campo Grande, no Mato Grosso do Sul. Procurou-se detectar as suas práticas pedagógicas, bem como as ações necessárias para contribuir com o processo de ensino e de aprendizagem das crianças hospitalizadas.

\section{ABORDAGEM METODOLÓGICA DA PESQUISA}

A partir das leituras, observação in loco, aplicação de entrevista semiestruturada e análise das informações obtidas durante a realização da pesquisa, durante o ano 2017, foi possível apresentar os dados e os resultados da ação que foi realizada no Hospital Universitário (HU) em Campo Grande, no Mato Grosso do Sul, no mês de outubro/2017, com 03 (três) professoras atuantes na classe hospitalar. De acordo com Neves: 


\section{autêntica}

DOI https://doi.org/10.31639/rbpfp.v\%vi\%i.34

Em primeiro lugar a pesquisa qualitativa não apresenta preocupação com um grande número de dados, pois não há preocupação em demonstrar resultados para a população. Assim, entendemos que a pesquisa qualitativa tem como principal objetivo interpretar o fenômeno em observação (NEVES, 2015, p. 19).

Os elementos metodológicos utilizados para a realização da pesquisa envolvem estudo bibliográfico de artigos relacionados à temática da discussão proposta, com uso de descritores para filtrar e selecionar os arquivos, tais como: "classe hospitalar"; "práticas pedagógicas na classe hospitalar", "formação de professores da classe hospitalar", "atendimento pedagógico nas classes hospitalares", além dos documentos legais que garantem o atendimento pedagógico para crianças hospitalizadas, documentos que foram consultados para fundamentar o trabalho e constam nas referências.

Com uma abordagem qualitativa, a pesquisa apresenta os dados levantados a partir da atuação in loco, com observação do espaço destinado à prática pedagógica e das relações sociais no ambiente que envolve aluno $\mathrm{x}$ professor, professor $\mathrm{x}$ professor, professor $\mathrm{x}$ equipe hospitalar. Essa observação realizada considera que essas não são as temáticas centrais da investigação, mas que perpassam o processo de ensino-aprendizagem das crianças internadas e que interferem, de forma significativa, nas práticas pedagógicas dos professores da classe hospitalar. Para Pesce e André:

Saber diagnosticar, levantar hipóteses, buscar fundamentação teórica e analisar dados são algumas das atividades que podem ajudar o trabalho do professor, quando se consideram as exigências da realidade atual e a complexidade da atividade da docência. Nessa perspectiva, é imprescindível que o preparo específico para a pesquisa já ocorra na formação inicial (PESCE; ANDRÉ, 2012, p. 41).

Nessa perspectiva, é possível compreender a importância da pesquisa na formação inicial do professor, de maneira que amplie os conhecimentos e propicie ao profissional mecanismos para que haja uma mobilização, interna e externa (na subjetividade), de maneira que, ao se deparar com a realidade docente, compreenda que há possibilidades de produzir conhecimentos e não apenas uma inserção no sistema de "reprodução" e "receitas".

\section{CONTEXTO DA INVESTIGAÇÃO}

No mês de outubro de 2017, no período matutino, foi iniciada a observação in loco com o intuito de obter informações acerca das práticas pedagógicas desenvolvidas na classe hospitalar da pediatria do Hospital Universitário de Campo Grande/MS, após autorização tanto do comitê de ética da plataforma Brasil, como também do próprio hospital.

De acordo com as informações obtidas da professora responsável no momento da observação (professora que aqui será identificada como $\mathrm{M}$, para preservar a sua identidade), a classe hospitalar atualmente atende em salas e leitos dos setores de pediatria, de isolamento e de oncologia, sendo:

\footnotetext{
- Clínica Médica (a partir de 14 anos);

- Cirúrgica I e II (ortopédicos);

- PAM (sala pequena com poucos recursos);

- Pulsoterapia;

- Hemodiálise (no momento da pesquisa, estava em reforma);

- DIP (doenças infectocontagiosas).
} 


\section{autêntica}

DOI https://doi.org/10.31639/rbpfp.v\%vi\%i.34

No ambiente foi possível observar as questões estruturais, que refletem na prática docente bem como na organização de tempo. O horário das atividades segue um cronograma, assim organizado:

- Período matutino: das 07h:30 min. às 09h:30 min. (aula)/ das 09h:30 min. às 09:h:50 min (intervalo)/ das 09h:50min. às $11 \mathrm{~h}: 30 \mathrm{~min}$. (aula).

- Período vespertino: das 13h:00min às 15h:30min. (aula)/ 15h:30min. às 15h:50min. (intervalo)/ 15h:50min. às $17 \mathrm{~h}: 00 \mathrm{~min}$. (aula).

A pediatria possui dezessete (17) leitos e uma (01) sala destinada ao funcionamento das aulas. O atendimento é realizado na sala, entretanto, é considerado cada caso e, se houver a necessidade, a aula pode ocorrer no leito. Acerca do espaço físico destinado às aulas, foi possível observar que o ambiente possui:

- Um (01) aparelho televisor;

- Mesas para crianças pequenas;

- Mesas para crianças maiores;

- Dois (02) computadores com acesso à internet (para uso didático):

- Um (01) armário para materiais dos professores;

- Duas (02) estantes amplas para brinquedos;

- Uma (01) estante para jogos pedagógicos, como quebra-cabeças e dominó;

- Duas (02) estantes com livros didáticos e paradidáticos;

- Nas paredes ainda há cartazes com famílias silábicas, mapa e informativo de doença (dengue);

-Banheiro para uso dos professores,

- Material para higiene das mãos (álcool em gel).

A observação da estrutura da classe hospitalar, em funcionamento no HU, permitiu perceber que há conformidade com as recomendações propostas no documento do MEC intitulado "Classe Hospitalar e Atendimento Pedagógico Domiciliar: estratégias e orientações" (BRASIL, 2002, p. 15-16):

Os ambientes serão projetados com o propósito de favorecer o desenvolvimento e a construção do conhecimento para crianças, jovens e adultos, no âmbito da educação básica, respeitando suas capacidades e necessidades educacionais especiais individuais. Uma sala para desenvolvimento das atividades pedagógicas com mobiliário adequado e uma bancada com pia são exigências mínimas. Instalações sanitárias próprias, completas, suficientes e adaptadas são altamente recomendáveis e espaço ao ar livre adequado para atividades físicas e ludo-pedagógicas.

Além de um espaço próprio para a classe hospitalar, o atendimento propriamente dito poderá desenvolver-se na enfermaria, no leito ou no quarto de isolamento, uma vez que restrições impostas ao educando por sua condição clínica ou de tratamento assim requeiram.

O atendimento pedagógico poderá também ser solicitado pelo ambulatório do hospital onde poderá ser organizada uma sala específica da classe hospitalar ou utilizar-se os espaços para atendimento educacional.

Nas classes hospitalares, sempre que possível, devem estar disponibilizados recursos audiovisuais, como computador em rede, televisão, vídeo-cassete, máquina fotográfica, filmadora, videokê, antena parabólica digital e aparelho de som com CD e k7, bem como telefone, com chamada a ramal e linha externa. (BRASIL, 2002, p. 15-16). 


\section{autêntica}

DOI https://doi.org/10.31639/rbpfp.v\%vi\%i.34

Tendo encontrado essa realidade, é possível afirmar que a sala para a classe hospitalar possui elementos pedagógicos que podem propiciar um processo de ensino-aprendizagem com qualidade para o educando que passa por internação no local.

No momento da observação, havia quatro crianças dos anos iniciais do Ensino fundamental que foram observadas durante todo o período da pesquisa, e elas são aqui identificadas como A1, A2, A3 e A4, para preservar a identidade das mesmas. Inicialmente, para que ocorra o atendimento na classe hospitalar envolve o preenchimento de ficha do estudante conforme conversa com o seu responsável. Caso o período da internação seja presumido como longo, é feito contato com a escola e solicitado que sejam encaminhadas as atividades elaboradas pelo professor regente, para que possam ser realizadas no hospital durante o atendimento pedagógico.

Durante o atendimento, as crianças A1 (frequenta o $3 .^{\circ}$ ano do ensino fundamental I) e A2 (frequenta o $4 .^{\circ}$ ano do ensino fundamental I), tiveram aula na sala destinada para o atendimento. A criança A3 (frequenta o $2{ }^{\circ}$ ano do ensino fundamental I) não recebeu atendimento devido à situação em que estava, pois demonstrou cansaço e solicitou para voltar ao leito, afirmando que não desejava estudar naquele momento. A vontade da criança foi respeitada e ela retornou para o quarto com a mãe. Desse modo é possível compreender o que Silva (2015) aponta:

Assim, os espaços hospitalares também são, para as crianças, espaços de constituição de identidade, ou seja, de que forma as condições sociais, vividas nos hospitais, configuram a construção da identidade social da criança, a forma como se define a si e aos outros, se revê enquanto cidadão, titular de direitos e responsabilidades, direitos esses garantidos pela proteção à criança que significa envolvê-la mais diretamente [...]. (p. 27).

As crianças A1 e A2 estudaram os conteúdos de acordo com seu ensalamento e o Referencial Curricular de Educação Básica, previsto pela Secretaria Estadual de Educação (SED). Entretanto, de acordo com as informações da professora $\mathrm{M}$, a maioria das crianças recebidas está matriculada no município, mas a demanda não se restringe à capital, pois no hospital são internadas crianças de todo o estado de Mato Grosso do Sul.

No momento, havia duas professoras e cada uma ficou responsável pela regência da aula para cada criança. Dessa forma, o atendimento foi individualizado, o que permitiu a percepção de interação e da proximidade entre educador e educando. Na realização das atividades, as professoras demonstraram que possuem um planejamento prévio e que prevê o uso de diferentes recursos pedagógicos.

A professora $\mathrm{M}$ direcionou atividades de matemática (subtração) para a estudante $\mathrm{A} 1$, com uso de material impresso, em um processo dialógico. A professora e a estudante conversaram acerca da operação que constava nos exercícios, de maneira que, durante a conversa, a criança demonstrava que refletia sobre o cálculo, a forma como chegava ao resultado e se estava correta sua resposta. No decorrer da atividade, a estudante olhou para professora aparentando satisfação, por ter alcançado a proposta da atividade e, disse: "Vou mostrar pra minha mãe isso daí" (A1). Nesse sentido, é possível compreender a importância do fazer pedagógico em ambiente hospitalar, conforme é apontado na citação abaixo:

A realização de práticas pedagógicas com criança enferma é um grande avanço, visto que, a partir da relação entre família, equipe médica e equipe educacional, é propiciada a continuidade de um projeto de vida e o desenvolvimento do conhecimento infantil e realização pessoal das crianças. (SILVA, 2015, p. 42). 


\section{autêntica}

DOI https://doi.org/10.31639/rbpfp.v\%vi\%i.34

Em outro momento, a professora $\mathrm{M}$ disponibilizou uma folha em branco para que a criança desenhasse algo de seu interesse. Então A1 iniciou o desenho de um skate, afirmando que não sabia andar, mas que gostava do objeto. Entretanto, logo em seguida, uma enfermeira chegou à sala e solicitou que a criança retornasse ao quarto para realizar um procedimento recomendado pelo médico. A1 demonstrou não querer retornar para o leito, queria continuar suas atividades. Com diálogo feito pela professora e enfermeira, deixando a sala disposta para dar continuidade após o procedimento, a criança dirigiu-se para o quarto. Esse pequeno evento permite compreender a questão apontada,

[...] implica que o reconhecimento de projetos que disponibilizem recursos à criança hospitalizada um atendimento pedagógico capaz de fazer com que a criança não se sinta incapaz e impossibilitada de realizar atividades, assim o atendimento pedagógico realizado no ambiente hospitalar deverá se concretizar com atividades que envolvam o processo de desenvolvimento físico, cognitivo e emocional, para que estes não se interrompam frente à doença, mas, sim, que ganhe novas perspectivas frente à realidade atual da criança. (CALEGARI-FALCO, 2007, p. 4286).

Articulando o pensamento de Calegari-Falco por meio da observação desse fato, é possível perceber que a prática pedagógica realizada pela professora M aproximou $\mathrm{A} 1$ de seu contexto escolar vivido antes da internação e que permite a "reconexão" com o mundo externo.

Houve também acompanhamento da aula direcionada para A2, nesse caso com a professora $\mathrm{N}$ (aqui sua identidade será mantida dessa forma, para preservação da mesma). As atividades que foram elaboradas para a estudante eram de Língua Portuguesa com o conteúdo de "substantivos coletivos". Inicialmente, a professora apresentou para a estudante o conteúdo que seria trabalhado, mostrou a atividade impressa (usada como registro). Após, com diálogo, o trabalho foi o de buscar os conhecimentos prévios da criança e a resolução dos exercícios. Um fato interessante foi o uso do dicionário e da internet como recursos para que A2 buscasse as informações acerca dos substantivos coletivos que desconhecia. Esse processo apresentou-se com participação e interação constante entre professora e estudante. Nesse momento foi possível perceber a criança como centro do processo educativo e a professora como mediadora do conhecimento.

Conforme já pontuado anteriormente, a criança $A 3$, naquele dia, informou às professoras que não desejava participar das atividades. Ela então pôde retornar para o leito. A partir dessa situação, foi possível compreender que as práticas de um professor atuante na classe hospitalar também estão ligadas a uma visão humanizada, uma visão que precisa considerar todo o contexto da criança e as questões que concernem ao seu estado biopsicossocial, para que, tanto o processo de internação, como o de continuidade aos estudos e de produção de conhecimentos, sejam menos enfadonhos e desgastantes:

[...] a Classe Hospitalar trabalha com a criança em si, como um sujeito único que tem sentimentos e esses deve ser respeitados, quando a criança percebe que estão respeitando os seus sentimentos, ela tende a ter uma confiança maior em quem está a sua volta, isso com certeza irá auxiliá-la na recuperação. (CALEGARI-FALCO, 2007, p. 4288).

Desse modo, há de se compreender que as práticas pedagógicas na classe hospitalar não se restringem aos recursos materiais (livros didáticos, paradidáticos, jogos, brinquedos tecnológicos, dentre outros), mas que essas práticas desenvolvidas pelo professor para com as crianças hospitalizadas vão muito além de conteúdo, mas capaz de uma aproximação de modo que se compreendam os aspectos inerentes ao aprendizado, à causa da internação, bem como aos procedimentos que são realizados pela equipe médica (multidisciplinar). Assim, as ações que são realizadas considerem todo o contexto vivido pela criança. 


\section{autêntica}

DOI https://doi.org/10.31639/rbpfp.v\%vi\%i.34

No leito da criança A4 foi possível acompanhar o atendimento pedagógico realizado pela professora $M$, que já havia separado, em uma prancheta, as atividades impressas, de Matemática e de Língua Portuguesa, direcionadas para o estudante, pois o mesmo não podia sair de seu leito.

A professora informou que já conhecia o estudante há algum tempo, pois que, devido ao seu caso de saúde, a criança passa por internações recorrentes desde muito pequeno. Atualmente está com a idade de treze (13) anos e, com matricula regular no $2^{\circ}$ ano do Ensino Fundamental dos Anos Iniciais. As atividades escolhidas pela professora foram: "antecessores e sucessores" e escrita de palavras a partir de desenhos.

O estudante realizou a atividade com auxilio constante da professora, que dialogou e apontou os caminhos para que a criança alcançasse os resultados dos exercícios. Foi possível perceber que o papel do atendimento pedagógico na classe hospitalar e as práticas pedagógicas em si, possuem grande importância para a continuidade dos estudos da criança internada, mas que também possibilita um atendimento individualizado que pode contribuir com um aprendizado com índices menores no que concerne às dificuldades na aprendizagem, visto que, para a criança, a hospitalização recorrente interfere de forma significativa na formação discente e na aquisição dos conhecimentos dispostos em sala de aula:

Sendo assim, é importante se ter a idéia do hospital como espaço de educação para as crianças hospitalizadas, uma vez que neste ambiente também podem ocorrer práticas que propiciam o desenvolvimento da mesma. Além disso, a educação não é um fenômeno exclusivamente escolar. (ANTUNES et al., p. 4034).

Durante a realização do atendimento pedagógico na classe hospitalar, as professoras demonstraram optar por uma prática que considera as particularidades de cada indivíduo, com o intuito de mediar o processo de aprendizagem do estudante de forma significativa e que contribua com a redução das dificuldades de aprendizagens que possam surgir em decorrência da internação.

\section{DISCUSSÃO DOS DADOS DA PESQUISA}

Durante o período da pesquisa foi aplicado um roteiro com sete questões semiestruturadas, com o intuito de obter mais informações acerca da prática pedagógica dos professores da classe hospitalar. A partir dos dados obtidos, foi possível observar que as três professoras que atuam na pediatria do Hospital Universitário são graduadas em Pedagogia, sendo que duas delas desempenham a função como pedagoga há cerca de 23 anos e ambas afirmaram atuar na classe hospitalar desde 2005. A terceira informou que finalizou a graduação há apenas um ano e há apenas quatro meses trabalha especificamente na classe hospitalar do HU.

No roteiro ainda foi questionado sobre eventual formação continuada, ao que uma das professoras informou que possui curso de especialização em Educação Especial e curso em Pedagogia Hospitalar; outra informou que possui curso de especialização em Educação Especial e, enfim, a terceira respondeu que possui especialização em Métodos e Técnicas de Ensino e que está em andamento a especialização em Educação Especial, bem como, em fase de conclusão uma especialização em Pedagogia Hospitalar.

Um dado que chama a atenção está ligado à questão dos conhecimentos teóricos e práticos relacionados à classe hospitalar durante a formação inicial, para embasamento na atuação dentro do hospital com as crianças internadas. Todas as professoras responderam que, durante a graduação, não estudaram conteúdos acerca desse assunto, ou seja, de acordo com as informações obtidas no roteiro de questões, a estrutura 


\section{autêntica}

DOI https://doi.org/10.31639/rbpfp.v\%vi\%i.34

curricular seja das professoras formadas há 23 anos, seja da professora formada recentemente, não disponibilizou disciplinas que contemplassem estudos norteadores das práticas de ensino-aprendizagem para os pedagogos dentro dos hospitais. A partir da análise dos dados apresentados, é possível perceber que, para atuar na classe hospitalar, as professoras precisaram buscar uma preparação que não foi disponibilizada na formação inicial, além de um curso de pós-graduação, o que permite pensar que se faz necessária a inserção de conteúdos, disciplinas e até reorganização na estrutura dos cursos de Pedagogia, pois a atuação dos professores é importante para o processo de ensino-aprendizagem:

A formação do professor da Classe Hospitalar assume a dimensão de uma educação inclusiva, pois deve trabalhar as potencialidades das crianças nos diferentes níveis e modalidades de educação, deve explorar todas as maneiras de atendimento pedagógico. Nesse sentido, a formação deve ser trabalhada acompanhando o processo de humanização da saúde e do direito à educação para todos. ( CALEGARI-FALCO, 2007, p. 4286-4287).

Nessa perspectiva, é possível compreender que a responsabilidade, as intervenções, as tomadas de decisão, a elaboração de atividades e a efetivação delas com as crianças internadas não são realizadas como em ambiente escolar. É certo que, os estudos acerca do desenvolvimento humano, com um olhar para a criança como um sujeito histórico e biopsicossocial, são alguns dos conhecimentos necessários para uma prática pedagógica que considere as necessidades dos indivíduos e que se realiza com maior ênfase na qualidade do processo de aprendizagem da criança. Entretanto, considerar que, em caso de internação, há o direito de continuidade dos estudos com o atendimento especializado e como precisam ser efetivadas as ações com as crianças que estão internadas, essas considerações contribuem de forma significativa para a formação dos professores da classe hospitalar e reflete em suas práticas pedagógicas, conforme documento da Secretaria de Educação Especial/MEC:

O professor deverá ter a formação pedagógica preferencialmente em Educação Especial ou em cursos de Pedagogia ou licenciaturas, ter noções sobre as doenças e condições psicossociais vivenciadas pelos educandos e as características delas decorrentes, sejam do ponto de vista clínico, sejam do ponto de vista afetivo. Compete ao professor adequar e adaptar o ambiente às atividades e os materiais, planejar o dia-a-dia da turma, registrar e avaliar o trabalho pedagógico desenvolvido. (BRASIL, 2002, p. 22).

Entretanto, para que esse atendimento continue sendo efetivado, é necessário que, durante a formação inicial, os profissionais tenham acesso aos conhecimentos inerentes à classe hospitalar e a percebam como um campo possível de atuação. Conforme as informações dos questionários, as professoras consideram o trabalho que realizam dentro do hospital importante: "Para continuação do desenvolvimento escolar do estudante que está hospitalizado, ajudando ele no que for necessário" (PROFESSORA N).

As três professoras afirmaram que as crianças reagem muito bem diante da presença das profissionais: "Elas reagem muito bem. Ficam entusiasmadas e, na maioria das vezes, querem começar logo. Essa interação entre alunos e professores ajuda na sua recuperação" (PROFESSORA M).

No que se refere às práticas pedagógicas que são desenvolvidas na classe hospitalar do HU em Campo Grande/MS, durante o período em que a pesquisa foi realizada e com as informações obtidas por meio dos questionários, quanto às professoras, todas formadas em Pedagogia, foi possível perceber que buscam, além dos cursos oferecidos pela SED/MS, complementar e suplementar a formação inicial, com informações sobre manipulação, manejo e cuidados com crianças doentes ou infectadas e dão importância à roda de conversas com a equipe multidisciplinar, elementos que se refletem na melhoria da prática docente. 


\section{autêntica}

DOI https://doi.org/10.31639/rbpfp.v\%vi\%i.34

Também foi possível compreender que as atividades são elaboradas semanalmente e de acordo com o Referencial Curricular da rede estadual de ensino. O plano de atividades/aula é elaborado, entretanto, de acordo com a solicitação da escola (em caso de longo período de internação). Além disso fazem uso de livros didáticos da rede municipal e privada de ensino, mas as atividades são adaptadas e flexíveis de forma que sempre considerarem a vontade e o quadro clínico, bem como a necessidade do cotidiano de cada criança.

O atendimento na classe hospitalar é multisseriado. Além das questões inerentes à patologia que a criança apresenta, as professoras analisam os momentos da aprendizagem de cada uma. O trabalho desenvolvido na classe hospitalar possibilita um contato efetivo e interação entre educador e educando, favorecendo a individualidade da criança no processo de ensino-aprendizagem e permitindo que a criança, muitas vezes, supere dificuldades que, no ambiente escolar, não foi possível superar. Conforme relatos das professoras, crianças que não liam ou que apresentavam dificuldades na aprendizagem, conseguiram avançar no que se refere à aquisição de conhecimentos escolares, fator que contribui para o desenvolvimento integral dos sujeitos envolvidos no processo.

Dentre as práticas pedagógicas, os recursos metodológicos são elementos fundamentais para que as aulas no hospital sejam realizadas de forma significativa e com qualidade. Quando questionadas acerca dos recursos utilizados, uma professora informou que faz uso de: jogos educativos, revistas, livros, jogos no computador, alfabeto móvel, xerox e brinquedos; outra professora respondeu que faz uso de jogos educativos, computador para pesquisas, atividades direcionadas e brinquedos; e a terceira respondeu que faz uso de atividades flexíveis adaptadas, jogos pedagógicos, internet, livros didáticos, computadores, vídeos, notebook, DVD e brinquedos. 


\section{autêntica}

DOI https://doi.org/10.31639/rbpfp.v\%vi\%i.34

\section{ALGUMAS CONSIDERAÇÕES}

Durante o acompanhamento das atividades foi possível perceber que as práticas pedagógicas direcionadas para A1, A2, A3 e A4 apresentaram um planejamento prévio e que foi pensado de forma individualizada para cada aluno de acordo com as necessidades de aprendizagem de cada um, sempre pautado no Referencial Curricular da Educação Básica proposto pela SED/MS.

A realização desta pesquisa não contribuiu apenas para a compreensão inicial de como está sendo desenvolvido o atendimento na classe hospitalar no $\mathrm{HU}$ e as práticas pedagógicas que são efetivadas no processo de ensino-aprendizagem, mas possibilita a reflexão acerca do modo como a classe hospitalar tem sido apresentada para os profissionais da educação durante o processo de sua formação inicial na licenciatura. Esse entendimento nos permite pensar que há fundamento em propor aprofundamento de estudos e pesquisas acerca da classe hospitalar e, até mesmo, a oferta desses estudos na estrutura curricular das universidades.

Este trabalho permite pensar que as práticas pedagógicas realizadas dentro de um ambiente hospitalar precisam ser previamente elaboradas e de acordo com as necessidades de cada criança, de maneira que possam contribuir para o processo de aprendizagem, seja com caráter complementar ou suplementar, mas que permita que a criança tenha continuidade nos estudos, como está disposto na legislação.

Todo o atendimento da classe hospitalar deve ser flexível, de acordo com a condição e possibilidade da criança, levando em consideração o tempo de internação, estado psicológico, patológico e capacidade de mobilidade, estes deveram contribuir para que, mesmo quando hospitalizada, a criança mantenha o elo com o mundo que ficou fora do hospital, para assim participar e aprender desfrutando de seu direito básico ao desenvolvimento pleno, independente de suas dificuldades, mas direcionado para o seu potencial, reduzindo o tempo de internação de forma a resgatar a sua auto-estima, amenizando o sofrimento causado pela internação. (CALEGARI-FALCO, 2007, p. 4287).

Nesse sentido, a pesquisa contribui para a compreensão de que o atendimento na classe hospitalar, bem como a ação docente, está ligado a questões que envolvem uma visão humanizada do indivíduo e que não há um modo único de fazer. É preciso entender as particularidades de cada criança e o seu estado clínico, para então pensar em cada ação, atividade, recursos e conhecimentos que serão direcionados, mas sempre considerando que a criança é um sujeito de direitos e que precisa ter suas necessidades temporárias ou definitivas atendidas com qualidade e significado. 


\section{autêntica}

DOI https://doi.org/10.31639/rbpfp.v\%vi\%i.34

\section{REFERÊNCIAS BIBLIOGRÁFICAS}

ANTUNES, R. C. R; CÉSAR, S.R; COSTA, C. C. A. et.al. O trabalho pedagógico realizado em ambiente hospitalar: análise de práticas educativas em hospitais de Belo Horizonte/MG. Curitiba, PR: Editora da PUC/PR, 2007. p. 4026-4075.

BARROS, A. S. S. e. Contribuições da educação profissional em saúde à formação para o trabalho em classes hospitalares. Cadernos Cedes, Campinas, vol. 27, n. 73, p. 257-278, set./dez. 2007.

BRASIL. Ministério da Educação. Classe hospitalar e atendimento pedagógico domiciliar: estratégias e orientações. / Secretaria de Educação Especial. Brasília, DF: MEC; SEESP, 2002.

BRASIL. Constituição da República Federativa do Brasil. Brasília, DF: Senado, 1988.

BRASIL. Lei n 9.394, de 20 de dezembro de 1996. Estabelece as Diretrizes e Bases da Educação Nacional. Diário Oficial [da] República Federativa do Brasil. Poder Executivo, Brasília, DF, v. 134, nº 248, p. 27833-27841, 23 dez. 1996.

BRASIL. Ministério dos Direitos Humanos. Conselho Nacional dos Direitos da Criança e do Adolescente. Resolução Conanda $n^{\circ}$ 41, de 13 de outubro de 1995. Dispõe sobre os direitos das crianças hospitalizadas. Diário Oficial da União, 1995.

BRASIL. Diretrizes Nacionais para Educação Especial na Educação Básica. Conselho Nacional de Educação. Brasília: MEC, 2001.

BRASIL. Estatuto das Crianças e do Adolescente. Lei Federal nº 8.069, de 13 de jul. 1990.

BRASIL. Ministério da Educação. Secretaria de Educação Especial. Política Nacional de Educação Especial. Brasília, DF: Secretaria de Educação Especial, 1994.

BRASIL. Conselho Nacional dos Direitos da Criança. Resoluções, junho de 1993 a setembro de 2004. Brasília, DF: Secretaria Especial dos Direitos Humanos, 2004. 200 p.

CALEGARI-FALCO, A. M. Classe hospitalar: a criança no centro do processo educativo. Anais do Educere/ PUC/2007 - Curitiba-PR. Disponível em: <www. pucpr.br/eventos/educere/educere2007/anaisEvento/arquivos/ PA-543-12.pdf>. Acesso em: 9 dez. 2016

DRABACH, N. P.; SOUZA, A. R. Leituras sobre a gestão democrática e o "gerencialismo" na/da educação no Brasil. Revista Pedagógica, v. 16, n. 33, jul./dez. 2014.

FONSECA, E. S. da. Atendimento pedagógico-educacional para crianças e adolescentes hospitalizados: realidade nacional. Brasília, DF: MEC/INEP, 1999.

NEVES, M. O. A importância da investigação qualitativa no processo de formação continuada de professores: subsídios ao exercício da docência. Revista Fundamentos, vol. 2, n. 1, 2015. Revista do Departamento de Fundamentos da Educação da Universidade Federal do Piauí. 


\section{autêntica}

DOI https://doi.org/10.31639/rbpfp.v\%vi\%i.34

PESCE, M. K. de; ANDRÉ. M. E. D. A. de. Formação do professor pesquisador na perspectiva do professor formador. Revista Brasileira de Pesquisa sobre Formação Docente. Belo Horizonte, vol. 4, n. 7, p. 39-50, jul./ dez. 2012.

SALDANHA, G. M. M. M; SIMÕES, R. R. Educação escolar hospitalar: o que mostram as pesquisas? Revista Brasileira Educação Especial. Marília, v. 19, n. 3, p. 447-464, Jul. - Set., 2013.

SANDRONI, G. A. Classe hospitalar: a importância do acompanhamento pedagógico para crianças e adolescentes. São Carlos: UFSCar, 2011.

SILVA, M. B. Trilhas pedagógicas articulam saúde e educação no desenvolvimento cognitivo infantil: criança com câncer. Campo Grande, MS: UFMS, 2015. 
